\title{
The Actual Level of Symptomatic Soft Disc Herniation in Patients with Cervical Disc Herniation
}

\author{
Su Yong Choi, Sang Gu Lee, Woo Kyung Kim, Seong Son, Tae Seok Jeong \\ Department of Neurosurgery, Gachon University Gil Medical Center, Incheon, Korea
}

\begin{abstract}
Objective: The aim of this study was to predict the relationship between the symptomatic disc herniation level and the osteophyte level or decreased disc height in patients with cervical disc herniation.

Methods: Between January 2011 and December 2012, 69 patients with an osteophyte of the cervical spine underwent surgery at a single center due to soft cervical disc herniation. Data including soft disc herniation level, osteophyte level in the posterior vertebral margin, Cobb's angle, and symptom duration were retrospectively assessed. The patients were divided into three groups according to the relationship between the degenerative change level and the level of reported symptoms.

Results: Among the 69 patients, $48(69.6 \%)$ showed a match between osteophyte level and soft disc herniation level. Disc herniation occurred at the adjacent segment to degenerative osteophyte level in 12 patients (17.4\%) and at both the adjacent and the osteophyte level in nine (13.0\%). There was no significant difference in Cobb's angle or duration among the three groups. Osteophyte type was not significant. The mean disc height of the prominent degenerative change level group was lower than the adjacent segment level, but this was not significant.

Conclusion: Soft cervical disc herniation usually occurs at the level an osteophyte forms. However, it may also occur at segments adjacent to that of the osteophyte level. Therefore, in patients with cervical disc herniation, although a prominent osteophyte alone may appear on plain radiography, we must suspect the presence of soft disc herniation at other levels.
\end{abstract}

Key Words: Intervertebral disc degeneration $\cdot$ Osteophyte $\cdot$ Intervertebral disc $\cdot$ Spinal fusion

\section{INTRODUCTION}

The lifetime prevalence of nuchal pain and upper extremity motor weakness, numbness, and radiating pain is estimated to be $12.1-71.5 \%{ }^{15)}$. The diagnosis and treatment of cervical disc herniation are associated with substantial health care costs. Intervertebral disc degeneration is associated with various morphological changes of the disc itself and the adjacent structures, such as collapse of the intervertebral space and sclerosis of the vertebral endplates or osteophytosis ${ }^{5,11)}$. Accordingly, it is possible to predict the cervical disc herniation level causing the patient's symptoms by plain radiography and

- Received: June 29, 2015 - Revised: August 4, 2015

- Accepted: August 5, 2015

Corresponding Author: Sang Gu Lee, MD, PhD

Department of Neurosurgery, Gachon University Gil Medical Center,

21, Namdong-daero 774beon-gil, Namdong-Gu, Incheon 21565, Korea

Tel: +82-32-460-3304, Fax: +82-32-460-3899

E-mail: samddal@gilhospital.com

అThis is an Open Access article distributed under the terms of the Creative

Commons Attribution Non-Commercial License (http://creativecommons.org/ licenses/by-nc/3.0/) which permits unrestricted non-commercial use, distribution, and reproduction in any medium, provided the original work is properly cited. magnetic resonance imaging. However, there are cases in which the cervical disc space narrowing and osteophyte seen on a plain radiograph does not match the actual disc herniation or dermatome level observed on initial neurological examination. Therefore, the purpose of this study is to predict the correlation between symptomatic disc herniation level and osteophyte level or decreased disc height in patients with cervical disc herniation.

\section{MATERIALS AND METHODS}

We retrospectively reviewed the clinical data of 69 consecutive patients who underwent surgery due to soft cervical disc herniation accompanied with osteophyte of the cervical spine at single center between January 2011 and December 2012. Inclusion criteria were the same as those for anterior cervical discectomy and fusion with radiculopathy and/or myelopathy and cervical vertebral osteophyte. Exclusion criteria were a history of cervical spine surgery, absence of osteophyte in the cervical spine, ossification of the posterior longitudinal ligament, inflammatory arthropathy such as rheumatoid arthritis, and fracture dislocation due to acute cervical trauma. 
This group of patients comprised 45 men and 28 women with a mean age of 50.7 years (range, 31-83 years). Each patient's chart was reviewed to determine the symptom duration and whether the onset of symptoms was spontaneous or associated with trauma. We also evaluated whether the symptoms were acutely aggravated, in which case the duration of aggravation was also recorded.

A neuroimaging evaluation was performed in all patients using plain radiography and magnetic resonance image (MRI). Plain radiography was used to note the prominent degenerative change level and disc height of the symptomatic herniated disc level shown on MRI. We measured the disc height as the length from the top of the lower vertebra to the bottom of the upper vertebra at the midpoint of the vertebral body on plain radiography. We also classified osteophyte shape on the vertebral posterior margin as round (mild degeneration without foraminal stenosis) or sharp (prominent bony spur with foraminal stenosis) using plain radiography (Fig. 1). The Cobb's angle obtained by measuring the angle formed by intersection

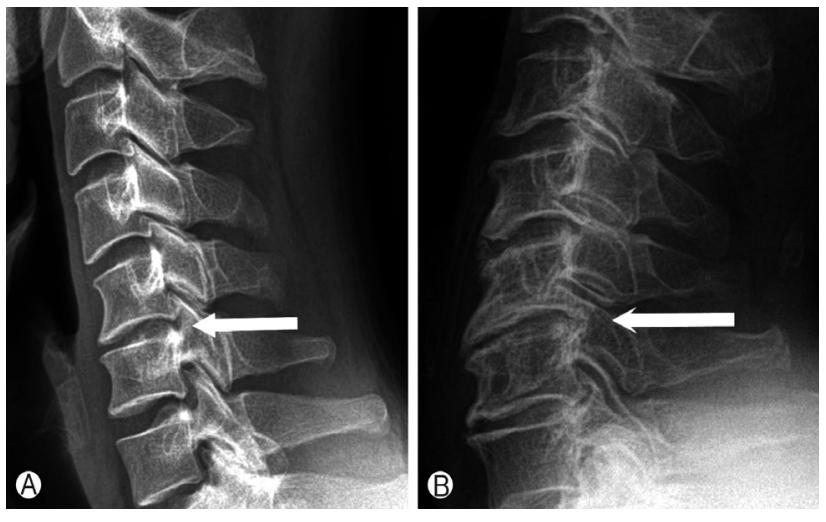

Fig. 1. Lateral view plain radiography of the cervical spine $(A)$ Round type osteophytes between C5 and 6 (white arrow) and (B) Sharp type osteophytes between C5 and 6 (white arrow). of the lines formed by the $\mathrm{C} 3$ upper margin and the $\mathrm{C} 7$ lower margin was used to compare cervical lordosis.

The patients were divided into three groups according to plain radiography and MRI findings. Group A included patients for whom the level responsible for their symptoms and the level of prominent degenerative change was a match (Fig. 2A). Group C included those patients who showed symptoms at a level adjacent to the site of prominent degenerative change, while Group B included patients who had both adjacent level and prominent degenerative change level disc herniation (Fig. 2B, C).

SPSS software version 19.0 (SPSS Inc., Chicago, IL, USA) was used. One-way analysis of variance (ANOVA) and a $\mathrm{X}^{2}$ test were used to compare the data. Values of $\mathrm{p}<0.05$ were considered to indicate statistical significance.

\section{RESULTS}

A total of 48 (69.9\%) out of 69 patients showed a match

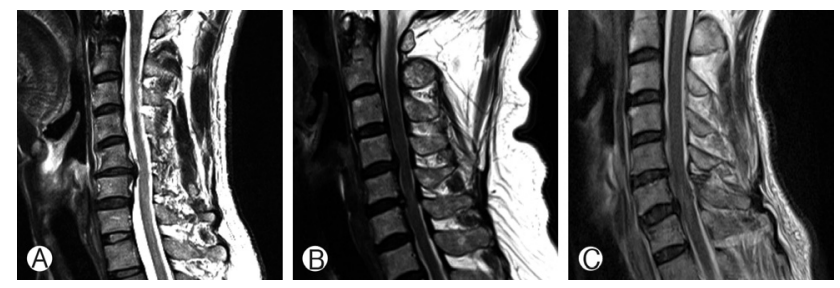

Fig. 2. Representative T2-weighted magnetic resonance images of each of the three groups. (A) Image of a match between the symptomatic cervical disc herniation and osteophyte levels and the level of prominent degenerative change at C5-6 (Group A). (B) Image for symptomatic disc herniation at C4-5 and C5-6. The osteophyte is at the level of prominent degenerative change at C5-6 and adjacent to the level of prominent degenerative change at C4-5 (Group B). (C) Image for symptomatic disc herniation at C6-7 with the osteophyte at C5-6 (Group C).

Table 1. Demographic data of patients

\begin{tabular}{|c|c|c|c|c|c|}
\hline & & Group $A^{*}$ & Group B ${ }^{+}$ & Group $\mathrm{C}^{\neq}$ & p-value \\
\hline Age (years) & & $49.9 \pm 10.7$ & $57.6 \pm 13.2$ & $48.6 \pm 8.6$ & 0.121 \\
\hline $\operatorname{Sex}(\%)$ & $\begin{array}{l}M \\
F\end{array}$ & $\begin{array}{l}33(62.3) \\
20(37.7)\end{array}$ & $\begin{array}{l}4(44.4) \\
5(55.6)\end{array}$ & $\begin{array}{l}8(72.7) \\
3(27.3)\end{array}$ & 0.426 \\
\hline Duration (weeks) & & $25.8 \pm 6.6$ & $58.9 \pm 12.9$ & $22.3 \pm 6.5$ & 0.204 \\
\hline Presence of symptom aggravation (No.(\%)) & $\begin{array}{l}\text { No } \\
\text { Yes }\end{array}$ & $\begin{array}{l}39(73.6) \\
14(26.4)\end{array}$ & $\begin{array}{l}8(88.9) \\
1(11.1)\end{array}$ & $\begin{array}{l}8(72.7) \\
3(27.3)\end{array}$ & 0.601 \\
\hline Aggravated period (days) & & $26.6 \pm 28.76$ & $15.0 \pm 0.0$ & $37.0 \pm 46.0$ & 0.806 \\
\hline Presence of trauma (No.(\%)) & $\begin{array}{l}\text { No } \\
\text { Yes }\end{array}$ & $\begin{array}{l}38(71.7) \\
15(28.3)\end{array}$ & $\begin{array}{l}6(66.7) \\
3(33.3)\end{array}$ & $\begin{array}{l}8(72.7) \\
3(27.3)\end{array}$ & 0.947 \\
\hline
\end{tabular}

Mean \pm SD, $\mathrm{n}(\%)$

"Prominent degenerative change level, ${ }^{\dagger}$ Prominent degenerative change level + Adjacent segment level, ${ }^{\ddagger}$ Adjacent segment level 
Table 2. Comparison of radiologic data among the 3 groups

\begin{tabular}{|c|c|c|c|c|c|}
\hline & & Group A* & Group B ${ }^{+}$ & Group $C^{+}$ & $\mathrm{p}$-valure \\
\hline Cobb's angle & & $13.0 \pm 9.0$ & $13.6 \pm 10.1$ & $14.3 \pm 9.7$ & 0.916 \\
\hline Osteophyte troe & Round & $29(59.2)$ & $1(11.1)$ & $6(54.5)$ & 0.061 \\
\hline Usteophyte type & Sharp & $20(40.8)$ & $8(88.9)$ & $5(45.5)$ & \\
\hline Degenerative change disc height (mm) & & $5.8 \pm 1.4$ & $5.9 \pm 0.9$ & $5.5 \pm 1.0$ & 0.694 \\
\hline Symptomatic disc height $(\mathrm{mm})$ & & $5.8 \pm 1.4$ & $6.1 \pm 0.7$ & $6.1 \pm 0.8$ & 0.785 \\
\hline
\end{tabular}

Mean \pm SD, $\mathrm{n}(\%)$

${ }^{*}$ Prominent degenerative change level, ${ }^{\dagger}$ Prominent degenerative change level + Adjacent segment level, ${ }^{\dagger}$ Adjacent segment level

between the symptomatic disc herniation and the level of prominent degenerative change (Group A). Among them, 12 (14.7 \%) showed symptomatic disc herniation in segments adjacent to the prominent degenerative change level (Group C), and nine (13.0\%) showed symptomatic disc herniation in both the degenerative change level and adjacent segment level (Group B). One-way ANOVA and a $x^{2}$ test were used to compare variables among the three groups as shown in Tables 1 and 2 .

The mean age of the patients in Group A was 49.9 \pm 10.7 , that in Group B was 57.6 \pm 13.2 , and that in Group C was $48.5 \pm 8.6$ years. There was no statistical correlation in age among the three groups. There was also no significant difference in sex among the groups. The average symptom duration from the initial onset to the day of the operation was 25.8 \pm 6.6 weeks for Group A, $58.9 \pm 12.9$ weeks for Group B, and $22.3 \pm 6.5$ for Group C. Fourteen (26.4\%) of the patients in Group A experienced acute aggravation in symptoms for an average of 26.6 \pm 28.7 aggressive days. One (11.1\%) patient in Group B experienced acute aggravation for 15 aggressive days. Three patients (27.3\%) presented acute symptom aggravation with $37.0 \pm 46.0$ aggressive days in Group C. There was no statistical significance in the data (Table 1).

A history of cervical trauma was found in 15 patients (28.3 $\%)$ in Group A, three patients (33.3\%) in Group B, and three patients (27.3\%) in Group C (Table 2).

The average Cobb's angle was $13.0 \pm 9.0^{\circ}$ for Group A, 13.6 $\pm 10.1^{\circ}$ for Group B, and $14.3 \pm 9.7^{\circ}$ for Group C.

In terms of osteophyte type, 20 patients (40.8\%) had round type osteophytes and $29(59.2 \%)$ had sharp type osteophytes in Group A, eight (88.9\%) had round type and one (11.1\%) had sharp type in Group B, and five (45.5\%) had round type and six (54.5\%) had sharp type in Group C (Table 2).

The degenerative change and symptomatic disc heights were also compared. In Group A, the degenerative change disc height and symptomatic disc height matched at $5.8 \pm 1.4 \mathrm{~mm}$.

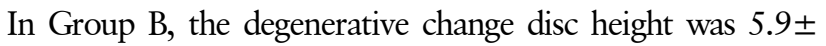
$0.9 \mathrm{~mm}$ and the symptomatic disc height was $6.1 \pm 0.7 \mathrm{~mm}$. In Group C, the degenerative change disc height was $5.5 \pm$ $1.0 \mathrm{~mm}$ and symptomatic disc height was $6.1 \pm 0.8 \mathrm{~mm}$. There was no significant correlation between disc heights in each group (Table 2).

\section{DISCUSSION}

The intervertebral disc connects two vertebral bodies by acting as a fibrocartilaginous joint that allows mobility in different directions and distributes the body's weight to the osseous structures $^{7}$. Each lamella of the annulus fibrosus consists primarily of collagen type I fibers that cross diagonally between vertebral bodies, and these collagen fibers are oriented in opposite directions in the adjacent lamellae ${ }^{4}$. The nucleus pulposus consists mainly of proteoglycans along with collagen type II and elastin fibers, which confer on the nucleus its very gel-like features. Aggrecan is the main proteoglycan of the disc ${ }^{21)}$, and its high anionic glycosaminoglycan content allows the disc to be very resistant to compression due to its osmotic properties.

The mechanisms of an intervertebral disc's internal function can be tested by the pulling of a miniaturized pressure transducer through it. The nucleus and annulus of a young disc have very high water content, and they behave much like a water bed. The outer annulus is very tensile, unlike the inner structures, and it functions to restrain the nucleus. As a person ages, the water content of the nucleus decreases dramatically and the annulus is burdened to resist direct compression as a fibrous solid. In disrupted discs, the degree of load bearing by the different regions of the fibrous tissue becomes irregular and the water-filled nucleus is nearly absent ${ }^{4}$.

As the intervertebral disc ages, many changes occur compared to the young, healthy disc, even in asymptomatic patients". Proteoglycan fragmentation starts as early as childhood ${ }^{6}$, and as the aging process progresses, the overall water content and proteoglycan level of the disc decreases, especially in the nucleus. The aging process also leads to a reduction in the percell synthesis rate that worsens with the loss of proteoglycan content, which is probably related to cell senescence ${ }^{14)}$. Such cellular and biochemical changes lead to changes in the extra- 
cellular matrix. In summary, during the entire aging process, the overall fibrotic tissue content increases as the water content decreases in the entire disc ${ }^{3,4)}$.

The intervertebral disc also accumulates clefts and tears, which eventually leads to structural failure ${ }^{20)}$. Osteophyte formation at the edge of the vertebral bodies is a common finding related to disc degeneration ${ }^{11,17,19)}$. Osteophyte forma- tion is believed to be part of an adaptive remodeling process in an effort to provide stability in unstable spine segments ${ }^{13)}$. Degenerative changes of the intervertebral disc leading to such structural changes are believed to be associated with spinal flexibility limitations ${ }^{12}$. The annulus height is another important factor that determines the separation of adjacent neural arches. The structural degeneration of the annulus in old discs can lead to an increase in compressive force by up to $50 \%$ on the lumbar spine being endured by the neural $\operatorname{arch}^{18)}$.

The extent of nucleus migration varies among protrusion, extrusion, and sequestration of the nuclear material. When a physiological limit is exceeded between the forces exerted on the disc as a result of bending and compression, the disc prolapses ${ }^{1)}$. Intense repetitive loading can also lead to disc prolapse ${ }^{2,8)}$. Mechanically induced disc prolapse occurs most commonly in discs of patients aged $30-40$ years ${ }^{8}$, which is the age at which the disc is still maintaining its water content but the annulus begins to weaken as its loses structural integrity. Prolapsed disc tissue primarily consists of nucleus pulposus displaced through the fissure in the annulus ${ }^{16}$.

Osteophyte formation as a result of disc height decreases induced by disc degeneration leads to flexibility limitations and causes structural changes that lead to an increased burden on adjacent discs. This is very similar to the mechanism of adjacent segment degeneration (ASD) after spinal fusion. ASD occurs in the disc segments near the level of spinal fusion as a combined result of restoration in motion after the operation and natural degeneration ${ }^{10)}$. We believe that the motion restriction caused by osteophyte formation and decreased disc height may play a role in adjacent disc degeneration and eventual disc rupture just as disc degeneration occurs in ASD.

\section{CONCLUSION}

Soft cervical disc herniation usually occurs at the level of osteophyte formation. However, soft disc herniation may also occur at segments adjacent to the osteophyte level. Although not statistically significant, the symptomatic adjacent disc herniation of the degenerative disc was $27.7 \%$ in patients who underwent anterior cervical discectomy and fusion. Therefore, in patients with cervical disc herniation, even though prominent osteophytes may apparent on a plain radiograph, we must suspect that soft disc herniation can occur in other levels as well. If symptoms develop along a new dermatome or the neurologic examination and radiography findings do not correlate, we believe that the patient should be carefully re-evaluated and an MRI evaluation should be considered.

\section{REFERENCES}

1. Adams MA, Freeman BJ, Morrison HP, Nelson IW, Dolan P: Mechanical initiation of intervertebral disc degeneration. Spine (Phila Pa 1976) 25:1625-1636, 2000

2. Adams MA, Hutton WC: Gradual disc prolapse. Spine (Phila Pa 1976) 10:524-531, 1985

3. Adams MA, McNally DS, Dolan P: 'Stress' distributions inside intervertebral discs. The effects of age and degeneration. J Bone Joint Surg Br 78:965-972, 1996

4. Adams MA, Roughley PJ: What is intervertebral disc degeneration, and what causes it? Spine (Phila Pa 1976) 31:2151-2161, 2006

5. Boos N, Weissbach S, Rohrbach H, Weiler C, Spratt KF, Nerlich AG: Classification of age-related changes in lumbar intervertebral discs: 2002 Volvo Award in basic science. Spine (Phila Pa 1976) 27:2631-2644, 2002

6. DeGroot J, Verzijl N, Wenting-van Wijk MJ, Jacobs KM, Van El B, Van Roermund PM, et al: Accumulation of advanced glycation end products as a molecular mechanism for aging as a risk factor in osteoarthritis. Arthritis Rheum 50:1207-1215, 2004

7. Galbusera F, van Rijsbergen M, Ito K, Huyghe JM, Brayda-Bruno $\mathrm{M}$, Wilke HJ: Ageing and degenerative changes of the intervertebral disc and their impact on spinal flexibility. Eur Spine J 23:S324-332, 2014

8. Gordon SJ, Yang KH, Mayer PJ, Mace AH, Jr., Kish VL, Radin EL: Mechanism of disc rupture. A preliminary report. Spine (Phila Pa 1976) 16:450-456, 1991

9. Haefeli M, Kalberer F, Saegesser D, Nerlich AG, Boos N, Paesold $\mathrm{G}$ : The course of macroscopic degeneration in the human lumbar intervertebral disc. Spine (Phila Pa 1976) 31:1522-1531, 2006

10. Hilibrand AS, Robbins M: Adjacent segment degeneration and adjacent segment disease: the consequences of spinal fusion? Spine J 4:190S-194S, 2004

11. Kettler A, Rohlmann F, Neidlinger-Wilke C, Werner K, Claes L, Wilke HJ: Validity and interobserver agreement of a new radiographic grading system for intervertebral disc degeneration: Part II. Cervical spine. Eur Spine J 15:732-741, 2006

12. Lee HB, Yoo CJ, Park CW, Lee SG, Kim WK: Clinical usefulness of disc degeneration and facet joint degeneration as an indicator of judgment for lumbar segmental instability. Kor J Spine 6:163-168, 2009

13. Lipson SJ, Muir H: Vertebral osteophyte formation in experimental disc degeneration. Morphologic and proteoglycan changes over time. Arthritis Rheum 23:319-324, 1980

14. Maeda S, Kokubun S: Changes with age in proteoglycan synthesis in cells cultured in vitro from the inner and outer rabbit 
annulus fibrosus. Responses to interleukin-1 and interleukin-1 receptor antagonist protein. Spine (Phila Pa 1976) 25:166-169, 2000

15. Manchikanti L, Nampiaparampil DE, Candido KD, Bakshi S, Grider JS, Falco FJ, et al: Do cervical epidural injections provide long-term relief in neck and upper extremity pain? A systematic review. Pain Physician 18:39-60, 2015

16. Moore RJ, Vernon-Roberts B, Fraser RD, Osti OL, Schembri M: The origin and fate of herniated lumbar intervertebral disc tissue. Spine (Phila Pa 1976) 21:2149-2155, 1996

17. Pfirrmann CW, Metzdorf A, Zanetti M, Hodler J, Boos N: Magnetic resonance classification of lumbar intervertebral disc degeneration. Spine (Phila Pa 1976) 26:1873-1878, 2001
18. Pollintine P, Przybyla AS, Dolan P, Adams MA: Neural arch loadbearing in old and degenerated spines. J Biomech 37:197-204, 2004

19. Thompson JP, Pearce RH, Schechter MT, Adams ME, Tsang IK, Bishop PB: Preliminary evaluation of a scheme for grading the gross morphology of the human intervertebral disc. Spine (Phila Pa 1976) 15:411-415, 1990

20. Vernon-Roberts B, Moore RJ, Fraser RD: The natural history of age-related disc degeneration: the pathology and sequelae of tears. Spine (Phila Pa 1976) 32:2797-2804, 2007

21. Watanabe H, Yamada Y, Kimata K: Roles of aggrecan, a large chondroitin sulfate proteoglycan, in cartilage structure and function. J Biochem 124:687-693, 1998 